\section{D) Check for updates}

Cite this: Dalton Trans., 2021, 50 7094

Received 27th March 2021, Accepted 27th April 2021

DOI: 10.1039/d1dt01013a rsc.li/dalton

\title{
Radical-initiated P,P-metathesis reactions of diphosphanes: evidence from experimental and computational studies $\uparrow$
}

\author{
Callum Branfoot, (D) a Tom A. Young, (D) ${ }^{b}$ Duncan F. Wass (D) ${ }^{c}$ and \\ Paul G. Pringle (iD) *a
}

\begin{abstract}
By combining the diphosphanes $\mathrm{Ar}_{2} \mathrm{P}-\mathrm{PAr}_{2}$, where $\mathrm{Ar}=\mathrm{C}_{6} \mathrm{H}_{5}, 4-\mathrm{C}_{6} \mathrm{H}_{4} \mathrm{Me}, 4-\mathrm{C}_{6} \mathrm{H}_{4} \mathrm{OMe}, 3,5-\mathrm{C}_{6} \mathrm{H}_{3}\left(\mathrm{CF}_{3}\right)_{2}$, it has been shown that $\mathrm{P}, \mathrm{P}$-metathesis generally occurs rapidly under ambient conditions. DFT calculations have shown that the stability of unsymmetrical diphosphanes $Z_{2} P-P Z_{2}^{\prime}$ is a function of the difference between the $Z$ and $Z^{\prime}$ substituents in terms of size and electronegativity. Of the mechanisms that were calculated for the P,P-metathesis, the most likely was considered to be one involving $\operatorname{Ar}_{2} \mathrm{P}^{\bullet}$ radicals. The observations that photolysis increases the rate of the P,P-metatheses and TEMPO inhibits it, are consistent with a radical chain process. The $\mathrm{P}, \mathrm{P}$-metathesis reactions that involve $(\mathrm{O}-\mathrm{Tol})_{2} \mathrm{P}-\mathrm{P}(\mathrm{O}-\mathrm{Tol})_{2}$ are anomalously slow and, in the absence of photolysis, were only observed to take place in $\mathrm{CHCl}_{3}$ and $\mathrm{CH}_{2} \mathrm{Cl}_{2}$. The role of the chlorinated solvent is ascribed to the formation of $\operatorname{Ar}_{2} \mathrm{PCl}$ which catalyses the P,P-metathesis. The slow kinetics observed with $(\mathrm{o}-\mathrm{Tol})_{2} \mathrm{P}-\mathrm{P}(\mathrm{O}-\mathrm{Tol})_{2}$ is tentatively attributed to the $\mathrm{O}-\mathrm{CH}_{3}$ groups quenching the $(\mathrm{O}-\mathrm{Tol})_{2} \mathrm{P}^{\bullet}$ radicals or inhibiting the metathesis reaction sterically.
\end{abstract}

\section{Introduction}

Dynamic and reversible chemical reactions have garnered increasing attention in medicine and biology, ${ }^{1}$ supramolecular chemistry $^{2}$ and materials science, ${ }^{3-11}$ and they are key to the rapidly growing field of dynamic covalent chemistry (DCC). ${ }^{1,12,13}$ In DCC, disulfides play a leading role, by virtue of the weakness of the S-S bond and their ready availability via chemical synthesis and their presence in natural products. ${ }^{12,14-16}$ In the last decade, several other main group element-element bonds $\left(\mathrm{O}-\mathrm{O},{ }^{17,18} \mathrm{~N}-\mathrm{N}^{19}\right.$ and $\left.\mathrm{Se}-\mathrm{Se}^{9,20,21}\right)$ have been investigated for their potential in dynamic chemistry with a view to their application in the field of polymeric materials. A notable omission from this group is diphosphanes $\left(\mathrm{P}_{2} \mathrm{R}_{4}\right)$ which contain a P-P bond whose strength $\left(c a .52 \mathrm{kcal} \mathrm{mol}^{-1}\right)^{22}$ is intermediate between S-S $\left(c a .62 \mathrm{kcal} \mathrm{mol}^{-1}\right)^{23}$ and Se-Se $\left(c a .40 \mathrm{kcal} \mathrm{mol}^{-1}\right)^{22}$ and therefore diphosphanes should be candidates for DCC.

Diphosphanes have received considerable attention as targets themselves and also as undesired byproducts in the syn-

\footnotetext{
${ }^{a}$ School of Chemistry, University of Bristol, Cantock's Close, Bristol BS8 1TS, UK. E-mail: paul.pringle@bristol.ac.uk

${ }^{b}$ Chemistry Research Laboratory, University of Oxford, Oxford OX1 3TA, UK ${ }^{c}$ Cardiff Catalysis Institute, School of Chemistry, Cardiff University, Cardiff CF1O 3AT, UK

$\dagger$ Electronic supplementary information (ESI) available. See DOI: 10.1039/ d1dt01013a
}

thesis of tertiary phosphines. ${ }^{24-31}$ Several methods to prepare diphosphanes are available, including: Wurtz-type reductive coupling of chlorophosphines (with $\mathrm{Li}, \mathrm{Na}, \mathrm{K}, \mathrm{Mg}$ and $\mathrm{Hg}$ ); ${ }^{32-34}$ salt metathesis between chlorophosphine and $\mathrm{LiPR}_{2}{ }^{26,27}$ dehydrocoupling of $\mathrm{HPR}_{2} ;{ }^{35-39}$ chlorosilane elimination; $;{ }^{40} \mathrm{P}-\mathrm{N} / \mathrm{P}-\mathrm{P}$ bond metathesis. ${ }^{41}$ The chemistry of diphosphanes can be divided into two categories: reactions where the $\mathrm{P}-\mathrm{P}$ bond remains intact and reactions where the P-P bonds are cleaved. ${ }^{42}$ Reactions involving P-P cleavage are pertinent to the chemistry described in this article and include additions of $\mathrm{X}_{2}$ to the $\mathrm{R}_{2} \mathrm{P}-$ $\mathrm{PR}_{2}$ to give monophos species $\mathrm{R}_{2} \mathrm{PX}($ e.g. $\mathrm{X}=\mathrm{H}, \mathrm{Cl})$ and additions of $\mathrm{R}_{2} \mathrm{P}-\mathrm{PR}_{2}$ to $\mathrm{C}=\mathrm{C}$ or $\mathrm{C} \equiv \mathrm{C}$ bonds (diphosphination) to give diphos species (Scheme 1). It has also been shown that diphosphanes containing $\mathrm{P}-\mathrm{N}$ bonds can add to $\mathrm{C}=\mathrm{S}$ or $\mathrm{C}=\mathrm{O}$ bonds. ${ }^{43,44}$ Mechanisms have been proposed for some of the $\mathrm{P}-\mathrm{P}$ cleavage reactions including radical chain processes. ${ }^{43,45}$

Diphosphane metathesis has not been systematically investigated, but an early ${ }^{31} \mathrm{P}$ NMR study by Harris et al. showed that rapid metathesis occurred between $\mathrm{Me}_{2} \mathrm{P}-\mathrm{PMe}_{2}$ and $\left(\mathrm{F}_{3} \mathrm{C}\right)_{2} \mathrm{P}-\mathrm{P}\left(\mathrm{CF}_{3}\right)_{2}$ in $\mathrm{CH}_{2} \mathrm{Cl}_{2}$ to form $\mathrm{Me}_{2} \mathrm{P}-\mathrm{P}\left(\mathrm{CF}_{3}\right)_{2} \cdot{ }^{46,47}$ Gilheany et $a{ }^{48}{ }^{48}$ have shown that the calculated high energy barrier to $\mathrm{P}, \mathrm{P}$-metathesis via a concerted mechanism is not compatible with the observed rapid kinetics for the $\mathrm{Me}_{2} \mathrm{P}-\mathrm{P}\left(\mathrm{CF}_{3}\right)_{2}$ system and suggested that pathways involving impurities in the diphosphanes may facilitate the P,P-metathesis process. Grubba et al. ${ }^{26}$ have succeeded in the preparation of a variety of pure, unsymmetrical diphosphanes containing $\mathrm{P}-\mathrm{C}($ alkyl) and $\mathrm{P}-\mathrm{N}$ bonds. By 


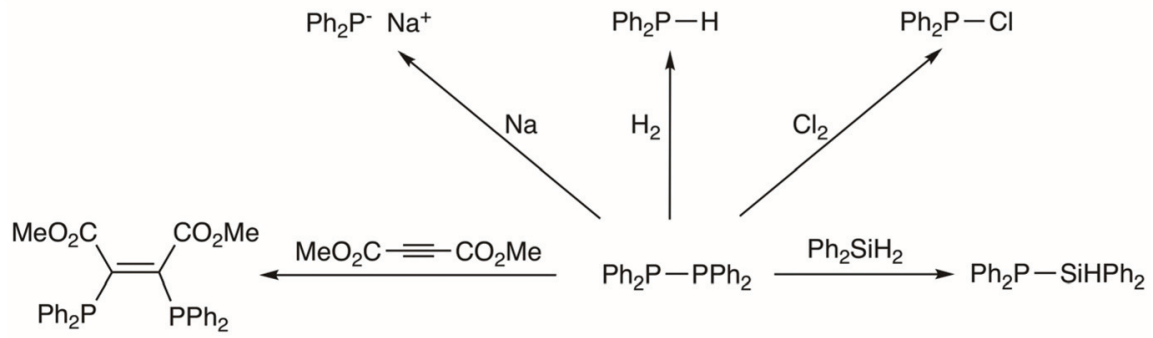

Scheme 1 Some reactions involving P-P cleavage of tetraphenyldiphosphane. ${ }^{42}$
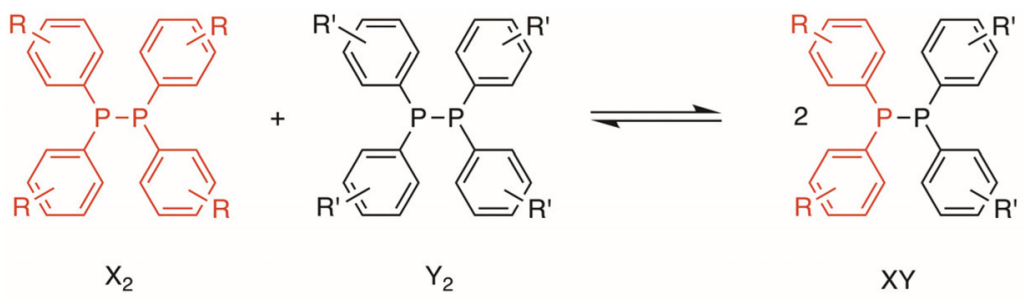

Scheme 2

employing low temperatures, they avoided unwanted P,P-metatheses that would lead to symmetrical diphosphanes contaminating the products. Moreover, they reported that $\mathrm{R}_{2} \mathrm{PCl}$ or $\mathrm{R}_{2} \mathrm{PLi}$ can catalyse diphosphane metathesis. We have reported that diphosphane metathesis was a side reaction in the attempted synthesis of some unsymmetrical diphosphanes. ${ }^{27}$

In this study, we have investigated the P,P-metathesis reactions of tetra-aryldiphosphanes (Scheme 2) using ${ }^{31} \mathrm{P}\left\{{ }^{1} \mathrm{H}\right\}$ NMR spectroscopy and computational methods, with a view to exploring the dynamic nature of these $\mathrm{P}-\mathrm{P}$ bonds. This has provided some new insights into the diphosphane metathesis reaction.

\section{Results and discussion}

\section{Thermodynamics of diphosphane metathesis}

Experimental equilibrium studies. The tetra-aryldiphosphanes $\mathbf{A}_{\mathbf{2}}-\mathbf{E}_{2}$ (Chart 1) used in this study, were chosen in order to sample a range of steric and electronic effects. All have been previously reported and were prepared by modified literature procedures for the reductive coupling of the corresponding chlorophosphines by $\mathrm{Mg}$ in THF (see ESI† for details). ${ }^{26,34}$ In each of the diphosphane samples, residual chlorophosphine was not detected by ${ }^{31} \mathrm{P}$ NMR spectroscopy and was therefore estimated to be less than $0.05 \%$ (see ESI $\dagger$ ).

When two of the diphosphanes $\mathbf{A}_{\mathbf{2}}-\mathbf{E}_{\mathbf{2}}$ were mixed in $\mathrm{CDCl}_{3}$ at ambient temperature, a reaction ensued to give an equilibrium mixture of homodiphosphanes $\mathrm{X}_{2}$ and $\mathrm{Y}_{2}$, and the heterodiphosphane XY (Scheme 2). The data for the diphosphane metathesis reactions are given in Table 1.

The ${ }^{31} \mathrm{P}\left\{{ }^{1} \mathrm{H}\right\}$ NMR data for the XY species (Table 1 ) show that the chemical shifts for the two signals are close to the respective $\mathrm{X}_{2}$ and $\mathrm{Y}_{2}$ with ${ }^{1} J_{\mathrm{XY}} \simeq 160 \mathrm{~Hz}$. For example, Fig. 1 is the ${ }^{31} \mathrm{P}\left\{{ }^{1} \mathrm{H}\right\}$ NMR spectrum obtained after mixing diphosphanes $\mathbf{B}_{2}$ and $\mathbf{C}_{2}$ (entry 4, Table 1 ) and shows the singlets for the reactants along with an $\mathrm{AB}$ pattern for the product $\mathbf{B C}$; the spectra for the other diphosphane combinations are given in the ESI. $\dagger$

The pure heterodiphosphane $\mathbf{A E}$ was prepared in order to establish the P,P-metathesis equilibrium with $\mathbf{A}_{\mathbf{2}}$ and $\mathbf{E}_{\mathbf{2}}$ (Scheme 2) from the opposite direction. Grubba et $a .^{26}$ have prepared a range of heterodiphosphanes $\left(\mathrm{Z}_{2} \mathrm{P}-\mathrm{PZ}_{2}^{\prime}\right)$ by the addition of $\mathrm{Z}_{2} \mathrm{PLi}$ to $\mathrm{Z}_{2}{ }_{2} \mathrm{PCl}$ at low temperatures. However, our attempts to extend this route to the preparation of $\mathbf{A E}$ were unsuccessful, even with the reaction mixture maintained at $-78{ }^{\circ} \mathrm{C}$ throughout; instead, an equilibrium mixture of $\mathbf{A}_{\mathbf{2}}, \mathbf{E}_{\mathbf{2}}$ and $\mathbf{A E}$ was obtained. This contrasting behaviour may be due to the lack of thermodynamic stability of heterodiphosphane AE compared with the Grubba heterodiphosphanes ${ }^{26}$ (see below). The desired AE was prepared in $>96 \%$ purity (after recrystallisation from methanol) via the protection/deprotection method (Scheme 3) that we previously developed for the synthesis of heterodiphosphanes. ${ }^{27,49}$ Solutions of pure $\mathbf{A E}$ in $\mathrm{CDCl}_{3}$ do indeed equilibrate to a mixture of $\mathbf{A}_{2}, \mathbf{E}_{2}$ and AE (see below for further details).

The diphosphane equilibrium constants for the P,P-metatheses (Scheme 2) fall in the range 3-30 (see Table 1), which corresponds to $\Delta G$ values between -0.5 and $-2 \mathrm{kcal} \mathrm{mol}^{-1}$, demonstrating that the diphosphanes in this study are very close in energy and insensitive to the steric and electronic effects of the aryl substituents. The equilibria that do not involve $\mathbf{E}_{2}$ were established rapidly (see Table 1) despite the dilution $(12.5 \mathrm{mM})$ which is a useful property for the potential application of diphosphanes in dynamic chemistry. ${ }^{1}$ The anomalously slow P,P-metatheses involving $\mathbf{E}_{2}$ are discussed later. 


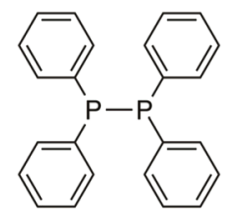

$A_{2}$

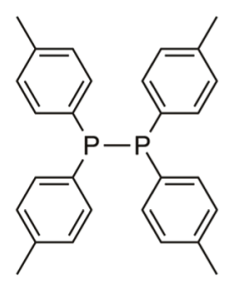

$\mathrm{B}_{2}$<smiles>COc1ccc(P(c2ccc(OC)cc2)P(c2ccc(OC)cc2)c2ccc(OC)cc2)cc1</smiles>

$\mathrm{C}_{2}$<smiles>FC(F)(F)c1cc(P(c2cc(C(F)(F)F)cc(C(F)(F)F)c2)c2cc(C(F)(F)F)cc(C(F)(F)F)c2)cc(C(F)(F)F)c1</smiles>

$\mathrm{D}_{2}$

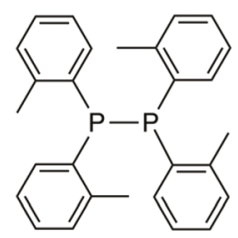

$E_{2}$

Chart 1

Table 1 Data for the P.P-metathesis equilibria shown in Scheme 2

\begin{tabular}{llllllll}
\hline Entry & $\mathrm{X}_{2}$ & $\mathrm{Y}_{2}$ & $K$ & Time $^{a} / \mathrm{min}$ & \multicolumn{3}{c}{${ }^{31} \mathrm{P}$ NMR data for XY } \\
\hline $1^{b}$ & $\mathbf{A}_{\mathbf{2}}$ & $\mathbf{B}_{2}$ & 4 & 30 & -14.9 & -16.4 & $J_{\mathrm{PP}}=162 \mathrm{~Hz}$ \\
$2^{c}$ & $\mathbf{A}_{2}$ & $\mathbf{C}_{2}$ & 5 & 20 & -15.9 & -18.4 & $J_{\mathrm{PP}}=159 \mathrm{~Hz}$ \\
$3^{d}$ & $\mathbf{A}_{\mathbf{2}}$ & $\mathbf{D}_{2}$ & $30^{e}$ & 90 & -15.9 & -8.5 & $J_{\mathrm{PP}}=177 \mathrm{~Hz}$ \\
$4^{d}$ & $\mathbf{B}_{2}$ & $\mathbf{C}_{2}$ & 4 & 15 & -16.8 & -18.8 & $J_{\mathrm{PP}}=156 \mathrm{~Hz}$ \\
$5^{b}$ & $\mathbf{B}_{2}$ & $\mathbf{D}_{2}$ & 15 & 20 & -11.7 & -15.7 & $J_{\mathrm{PP}}=165 \mathrm{~Hz}$ \\
$6^{b}$ & $\mathbf{C}_{2}$ & $\mathbf{D}_{2}$ & 3 & 20 & -10.5 & -15.4 & $J_{\mathrm{PP}}=173 \mathrm{~Hz}$ \\
$7^{c}$ & $\mathbf{A}_{2}$ & $\mathbf{E}_{2}$ & 4 & 700 & -16.6 & -35.3 & $J_{\mathrm{PP}}=152 \mathrm{~Hz}$ \\
$8^{c}$ & $\mathbf{B}_{2}$ & $\mathbf{E}_{2}$ & 4 & 1000 & -19.1 & -36.2 & $J_{\mathrm{PP}}=149 \mathrm{~Hz}$ \\
$9^{c}$ & $\mathbf{C}_{2}$ & $\mathbf{E}_{2}$ & 4 & 2800 & -19.0 & -36.9 & $J_{\mathrm{PP}}=148 \mathrm{~Hz}$ \\
$10^{c}$ & $\mathbf{D}_{\mathbf{2}}$ & $\mathbf{E}_{\mathbf{2}}$ & 30 & 4000 & -17.9 & -29.5 & $J_{\mathrm{PP}}=156 \mathrm{~Hz}$
\end{tabular}

${ }^{a}$ Time by which equilibrium had been established according to ${ }^{31} \mathrm{P}$ NMR spectroscopy. ${ }^{b}$ In THF. ${ }^{c}$ In $\mathrm{CDCl}_{3} .{ }^{d}$ In $\mathrm{C}_{6} \mathrm{D}_{6} .{ }^{e}$ Estimated value (see details in ESI $\dagger$ ).

Computational equilibrium studies. To understand better the factors that control the stability of heterodiphosphanes with respect to the corresponding homodiphosphanes, DFT calculations were carried out to determine the thermodynamics of the hypothetical equilibria shown in Scheme 4 in which the range of P-substituents $\mathrm{Z}$ and $\mathrm{Z}$ ' is greatly extended from the substituted aryls in Scheme 2. The values for $\Delta G$ are collected in Table 2, and for some of the combinations (Table 2, entries 1-3 and 7-10), the calculated $|\Delta G|$ is less than

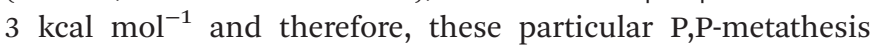
equilibria are predicted to be finely balanced. The calculated
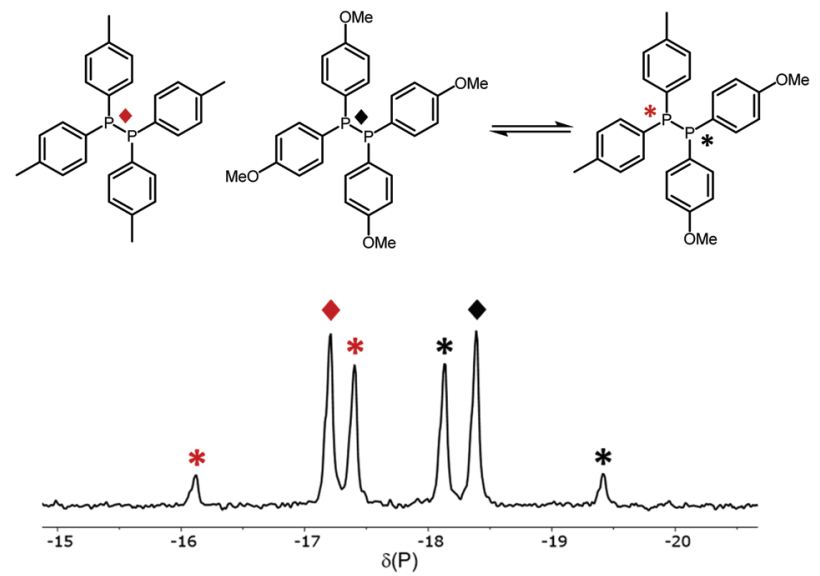

Fig. 1 The ${ }^{31} \mathrm{P}\left\{{ }^{1} \mathrm{H}\right\}$ NMR spectrum of the $\mathrm{P}, \mathrm{P}$-metathesis reaction between $(p-\mathrm{Tol})_{2} \mathrm{P}-\mathrm{P}(p-\mathrm{Tol})_{2}\left(\mathrm{~B}_{2}\right)$ and $(p \text {-Anisyl })_{2} \mathrm{P}-\mathrm{P}(p-\text { Anisyl })_{2}\left(\mathrm{C}_{2}\right)$.
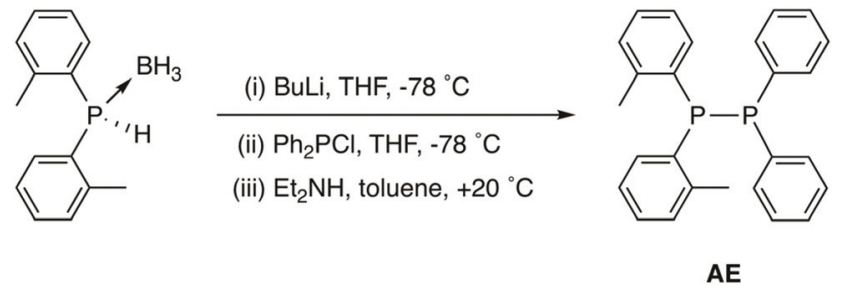

Scheme 3 


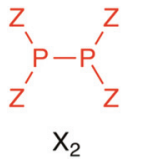<smiles>[Z]P([3H])P([Z])[3H]</smiles><smiles>[CH]=C</smiles>

$Y_{2}$

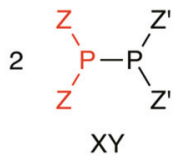

$X Y$
Scheme 4

Table 2 Calculated $\Delta G$ values for the diphosphane metathesis equilibria Scheme 4

\begin{tabular}{lllr}
\hline Entry & $\mathrm{Z}$ & $\mathrm{Z}^{\prime}$ & $\Delta G / \mathrm{kcal} \mathrm{mol}^{-1}$ \\
\hline 1 & $\mathrm{Me}$ & $\mathrm{H}$ & -0.5 \\
2 & $\mathrm{Me}$ & $\mathrm{NH}$ & -2.9 \\
3 & $\mathrm{Me}$ & $\mathrm{OH}$ & -2.9 \\
4 & $\mathrm{Me}$ & $\mathrm{OMe}$ & -3.7 \\
5 & $\mathrm{Me}$ & $\mathrm{F}$ & -6.6 \\
6 & $\mathrm{Me}$ & $\mathrm{CF}_{3}$ & -10.5 \\
7 & $\mathrm{Ph}$ & $\mathrm{H}$ & 0.8 \\
8 & $\mathrm{Ph}$ & $\mathrm{Me}$ & -0.7 \\
9 & $\mathrm{Ph}$ & $\mathrm{NH}_{2}$ & 1.3 \\
10 & $\mathrm{Ph}$ & $\mathrm{NMe}_{2}$ & -0.8 \\
11 & $\mathrm{Ph}$ & $\mathrm{OMe}$ & -4.7 \\
12 & $\mathrm{Ph}$ & $\mathrm{F}$ & -6.1 \\
13 & $\mathrm{Ph}$ & $\mathrm{CF}_{3}$ & -4.4 \\
14 & ${ }^{t} \mathrm{Bu}$ & $\mathrm{H}$ & -13.4 \\
15 & ${ }^{t} \mathrm{Bu}$ & $\mathrm{Me}$ & -3.3 \\
16 & ${ }^{t} \mathrm{Bu}$ & $\mathrm{Ph}$ & -4.0 \\
17 & ${ }^{t} \mathrm{Bu}$ & $\mathrm{NH}_{2}$ & -6.8 \\
18 & ${ }^{t} \mathrm{Bu}$ & $\mathrm{NMe}_{2}$ & -6.8 \\
19 & ${ }^{t} \mathrm{Bu}$ & $\mathrm{OMe}$ & -11.2 \\
20 & ${ }^{t} \mathrm{Bu}$ & $\mathrm{F}$ & -15.4 \\
21 & ${ }^{t} \mathrm{Bu}$ & $\mathrm{CF}_{3}$ & -3.4 \\
22 & ${ }^{o}-\mathrm{Tol}$ & $\mathrm{Ph}$ & 1.2
\end{tabular}

$\Delta G$ of $1.2 \mathrm{kcal} \mathrm{mol}^{-1}$ (Table 2, entry 22 ) for $\mathbf{A}_{2} / \mathbf{E}_{2}$ is remarkably close to the experimental value of $-0.8 \mathrm{kcal} \mathrm{mol}^{-1}$ obtained from the experimentally determined value of $K=4$ in $\mathrm{CDCl}_{3}$ solution (Table 1, entry 7).

Two gross trends emerge from the data in Table 2: (1) a bias in favour of the $\mathrm{XY}$ species is calculated when there is a large electronegativity difference between the $\mathrm{X}$ and $\mathrm{Y}$ fragments; thus $\mathrm{Me}_{2} \mathrm{P}-\mathrm{P}\left(\mathrm{CF}_{3}\right)_{2}$ is predicted (and experimentally observed $^{50}$ ) to be highly favoured (Table 2, entry 6); (2) a strong bias in favour of the $\mathrm{XY}$ species is calculated when there is a large difference in steric bulk between the $\mathrm{X}$ and $\mathrm{Y}$ fragments; thus ${ }^{t} \mathrm{Bu}_{2} \mathrm{P}-\mathrm{PH}_{2}$ is predicted to be highly favoured (Table 2, entry 13). The largest calculated $\Delta G$ in favour of the XY species is for ${ }^{t} \mathrm{Bu}_{2} \mathrm{P}-\mathrm{PF}_{2}$ (Table 2, entry 20), at an apparent apotheosis of both trends. The observed trends in the calculated relative stabilities of the $\mathrm{XY}$ species in Scheme 4 can be rationalised as follows: (a) electronegative $\mathrm{Z}$ substituents (such as F) will lead to repulsive electrostatic interactions between the $\delta+$ charges generated on the adjacent $\mathrm{P}$ atoms in diphosphane $\mathrm{X}_{2}$; (b) bulky $\mathrm{Z}^{\prime}$ substituents (such as ${ }^{t} \mathrm{Bu}$ ) will lead to steric congestion in diphosphane $\mathrm{Y}_{2}$; (c) in XY, both of the P-P bond-destabilising effects identified in (a) and (b) will be reduced and, in some cases, a destabilising, repulsive, electrostatic $(\delta+/ \delta+)$ interaction is replaced by a stabilising, attractive, electrostatic $(\delta+/ \delta-)$ interaction.
The calculated $\Delta G$ values for some of the Grubba heterodiphosphanes $^{26}$ (Table 2, entries 16 and 18) suggest that these should have high thermodynamic stability with respect to the corresponding homodiphosphanes. By contrast, the heterodiphosphine $\mathbf{A E}$, as reported above, is calculated to be of similar energy to the homodiphosphanes $\mathbf{A}_{\mathbf{2}}$ and $\mathbf{E}_{2}$ (Table 2, entry 22 ).

\section{Computational mechanistic studies of diphosphane metathesis}

The mechanism of the diphosphane metathesis shown in Scheme 5 has been previously investigated computationally by Gilheany $e t ~ a l^{48}$ The lowest energy route that they could find involved the ionic intermediate shown in Scheme 5 but the calculated barrier of $36.5 \mathrm{kcal} \mathrm{mol}^{-1}$ was too high to explain the rapidity of the P,P-metathesis that is observed experimentally.

We have investigated the mechanism of diphosphane metathesis computationally using the degenerate exchange reactions of $\mathrm{Me}_{2} \mathrm{P}-\mathrm{PMe}_{2}$ (Scheme 6). Tetramethyldiphosphane was chosen in order to limit the number of rotamers and thus the conformational noise in the calculations. It was hoped to distinguish between the three plausible pathways (i-iii) shown in Scheme 7: (i) a $[2+2]$ concerted process involving a 4-mem-

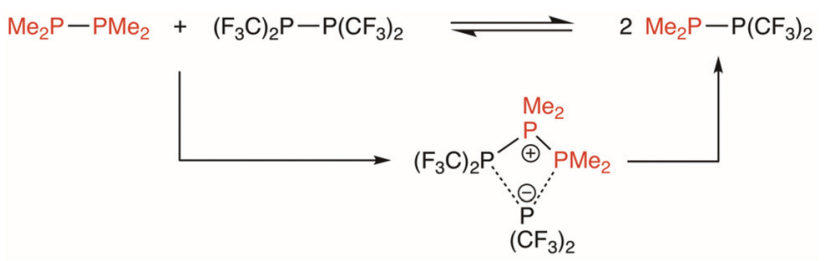

Scheme 5 Gilheany mechanism for a P,P-heterometathesis.

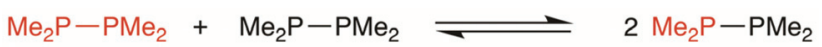

Scheme 6

(i)

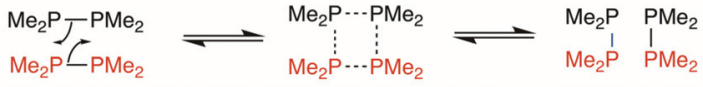

(ii)

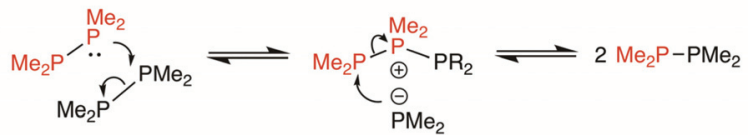

(iii)

$$
\mathrm{Me}_{2} \stackrel{\mathrm{P}}{\sim} \mathrm{PMe}_{2} \rightleftharpoons 2 \mathrm{Me}_{2} \dot{P}
$$

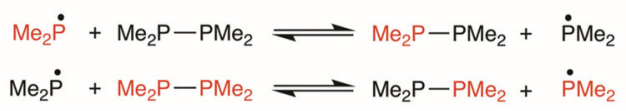

Scheme 7 

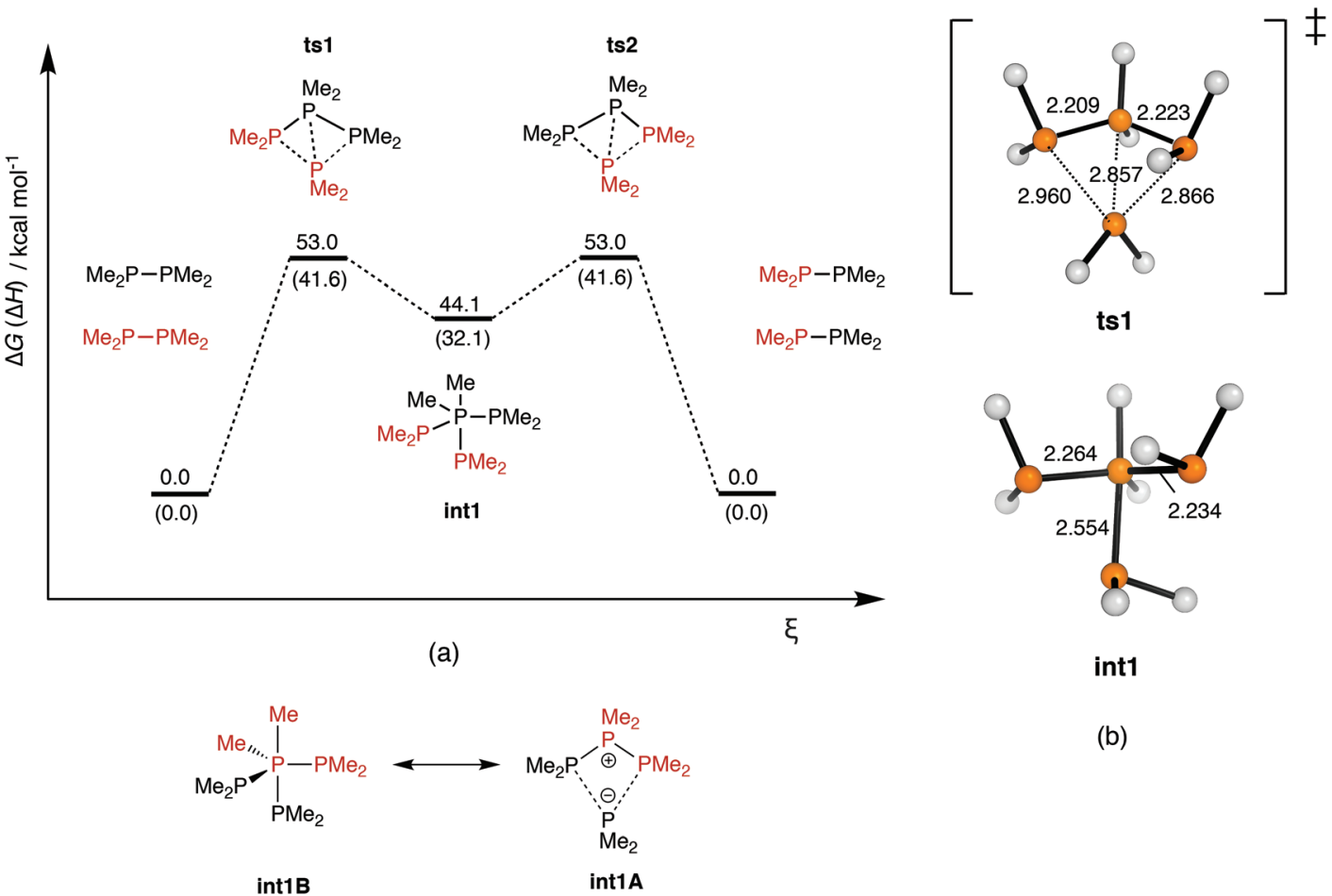

(c)

Fig. 2 (a) Reaction free energy profile for the P,P-homometathesis of $\mathrm{Me}_{2} \mathrm{P}-\mathrm{PMe}$. Calculations performed at the PBEO-D3BJ/def2-TZVPP/PBE0D3BJ/def2-SVP level of theory. (b) Calculated structures of ts1 and int1. Note: ts1 and ts2 are the same; key distances given in Å. (c) Resonance forms of int1.

bered intermediate or transition state; (ii) nucleophilic attack by one diphosphane on another to give an ionic intermediate (similar to the one suggested in Scheme 5); (iii) a $[2+1]$ radical chain process.

The overall reaction profile calculated for the thermal rearrangement of $\mathrm{Me}_{2} \mathrm{P}-\mathrm{PMe}_{2}$ (shown in Fig. 2(a) proceeds via intermediate int1 depicted in its lowest energy conformation in Fig. 2(b). The structure of int1 can be viewed in terms of the two resonance forms int1A and int1B shown in Fig. 2(c) (further details are given in the ESI $\dagger$ ). The ionic form int1A is analogous to the intermediate suggested for the P,P-heterometathesis shown in Scheme 5 and the covalent int1B contains an unusual central $\mathrm{P}(\mathrm{V})$ moiety. The profile shown in Fig. 2 corresponds to pathway (ii) of Scheme 7, and notably, attempts to locate a synchronous, $\sigma$-bond metathesis pathway (corresponding to pathway (i) in Scheme 7) were unsuccessful; no imaginary normal modes corresponding to the 2 bond-breaking/ forming vibrations are present along the relaxed, symmetric $\mathrm{P}_{4}$ ring expansion surface. The energy of int1 of $44.1 \mathrm{kcal} \mathrm{mol}^{-1}$ for the $\mathrm{PMe}_{2}$ species is lower for the analogous $\mathrm{PPh}_{2}$ intermediate $\left(\Delta G=38.1 \mathrm{kcal} \mathrm{mol}^{-1}\right.$, see ESI $\left.\dagger\right)$ but this is calculated to be not lowered by solvation with $\mathrm{CH}_{2} \mathrm{Cl}_{2}$. Thus, the calculated very high barrier is incompatible with the rapidity of the $\mathrm{Ar}_{2} \mathrm{P} \mathrm{PAr}_{2}$ metathesis reactions that is observed experimentally.

The radical chain pathway (iii) in Scheme 7 requires homolysis of a P-P bond. Thermolysis is not viable under ambient conditions because the calculated P-P bond enthalpy is of the order of $52 \mathrm{kcal} \mathrm{mol}^{-1}$. However, DFT calculations for $\mathrm{Ph}_{2} \mathrm{P}-$ $\mathrm{PPh}_{2}\left(A_{2}\right)$ suggest that excitation from $\mathrm{S}_{0} \rightarrow \mathrm{S}_{1}$ or $\mathrm{S}_{0} \rightarrow \mathrm{S}_{2}$ would result in rapid homolysis of the $\mathrm{P}-\mathrm{P}$ bond, yielding phosphanyl radicals $\left(\mathrm{Ar}_{2} \mathrm{P}^{*}\right)$ via intersystem crossing from $\mathrm{S}_{1}$ or $S_{2}$ to the first excited triplet state $\left(T_{1}\right)$ of $\mathbf{A}_{2}$; the $T_{1}$ state is dissociative, and would lead to spontaneous radical formation. From the $\mathrm{Ar}_{2} \mathrm{P}^{\circ}$, the $\mathrm{P}, \mathrm{P}-$ metathesis barrier generating $\mathrm{XY}$ species is only $\sim 5 \mathrm{kcal} \mathrm{mol}^{-1}$, such that once radicals are generated an equilibrium would be expected to be established rapidly (see ESI $\dagger$ for details).

The DFT results suggested that $\mathrm{Ar}_{2} \mathrm{P}^{\bullet}$ radicals (generated photolytically) were viable intermediates in the P,P-metathesis reactions and so this hypothesis was pursued experimentally.

\section{Qualitative experimental kinetic studies of diphosphane metathesis}

The aryl diphosphane metathesis reactions with $\mathbf{A}_{\mathbf{2}}-\mathbf{D}_{\mathbf{2}}$ occurred readily (typically $<1 \mathrm{~h}$ ) under ambient conditions in common organic solvents $\left(\mathrm{C}_{6} \mathrm{D}_{6}\right.$, THF, PhMe, $\mathrm{PhCl}, \mathrm{CDCl}_{3}$ and $\mathrm{CD}_{2} \mathrm{Cl}_{2}$ ). By contrast, when the diphosphane $\mathbf{E}_{2}$, containing $o$-tolyl substituents, was one of the reaction partners, P,P-metathesis was initially only observed to take place in $\mathrm{CDCl}_{3}$ (typically over 6-12 h) and $\mathrm{CD}_{2} \mathrm{Cl}_{2}$ (typically over more than $24 \mathrm{~h}$ ); the anomalous behaviour observed for the P,P-metatheses involving $\mathbf{E}_{2}$ will be discussed after consideration of the P,P-metatheses involving $\mathbf{A}_{2}-\mathbf{D}_{2}$. 
When cold $\left(-78^{\circ} \mathbf{C}\right)$ THF solutions of $\mathbf{B}_{2}$ and $\mathbf{C}_{2}$ were mixed and the $\mathrm{P}, \mathrm{P}$-metathesis reaction monitored by low-temperature ${ }^{31} \mathrm{P}$ NMR spectroscopy, it was found that only traces of $\mathbf{B C}$ were detected at $-80{ }^{\circ} \mathrm{C}$ after $1 \mathrm{~h}$. By raising the temperature in increments of $20^{\circ} \mathrm{C}$, it was established that the P,P-metathesis at $-20{ }^{\circ} \mathrm{C}$ progressed at a convenient rate to monitor the approach to $\mathrm{P}, \mathrm{P}$-metathesis equilibrium over a period of $2 \mathrm{~h}$ by ${ }^{31} \mathrm{P}$ NMR spectroscopy (see Fig. 3). Although a detailed kinetic study was not attempted, the data do not appear to fit a reaction order of 1, 2 or 0.5 (see ESI $\dagger$ ).

\section{Evidence for radicals in the general P,P-metathesis reactions}

In light of the computational results above suggesting that radicals may be involved in the mechanism of P,P-metathesis, experiments were carried out to determine if there was evidence of their presence. Two pieces of experimental evidence support the involvement of radicals in the P,P-metathesis process.

(1) When $\mathbf{A}_{2}$ and $\mathbf{C}_{2}$ were mixed in the presence of the radical scavengers 2,2,6,6-tetramethyl-1-piperidinyloxy (TEMPO) or tri(t-butyl)phenol (TTBP), the progress of the P,Pmetathesis reactions was greatly inhibited. Thus, a mixture of $\mathbf{A}_{\mathbf{2}}$ and $\mathbf{C}_{\mathbf{2}}$ proceeded smoothly to the metathesis equilibrium over a period of $2 \mathrm{~h}$ in $\mathrm{CDCl}_{3}$, at $-20{ }^{\circ} \mathrm{C}$ (with $35 \%$ conversion at $1 \mathrm{~h}$ ); by contrast, when the same $\mathbf{A}_{2} / \mathbf{C}_{2}$ mixture was prepared in the presence of 5 equiv. of TEMPO, there was no formation of AC detected after $1 \mathrm{~h}$. Moreover, when the reaction mixture containing TEMPO was allowed to warm to ambient temperature, $<10 \%$ of $\mathbf{A C}$ was detected even after $16 \mathrm{~h}$. Instead, in the presence of TEMPO, two singlet ${ }^{31} \mathrm{P}$ resonances at +30.5 and +31.5 ppm were observed ( $\mathrm{ca} .10 \%$ of the total signal intensity), consistent with the formation of $\mathrm{Ar}_{2} \mathrm{P}(\mathrm{O})$-TEMPO $(\mathrm{Ar}=\mathrm{Ph}$, $p$-anisyl) adducts (Scheme 8) which would be expected to be formed by the interception of the phosphanyl radicals $\left(\mathrm{Ar}_{2} \mathrm{P}^{*}\right)$ by TEMPO. ${ }^{51}$

(2) When $\mathbf{A}_{\mathbf{2}}$ and $\mathbf{B}_{\mathbf{2}}$ were mixed in a standard NMR tube in THF at ambient temperatures, equilibration was essentially complete within ca. $15 \mathrm{~min}$. However, when the same $\mathbf{A}_{\mathbf{2}} / \mathbf{B}_{\mathbf{2}}$ mixture in THF was prepared in an amberised NMR tube, to minimise the transmittance of UV and visible radiation, the

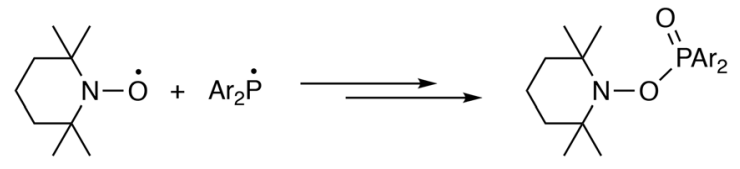

TEMPO

Scheme 8

equilibration to the same degree took $c a .150 \mathrm{~min}$. This is consistent with diphosphane photodissociation being a significant component of the mechanism of P,P-metathesis.

The UV-vis spectra of $\mathbf{A}_{2}, \mathbf{C}_{2}$ and $\mathbf{E}_{2}$ are shown in Fig. 4. Each spectrum has a major absorbance between 225 and $250 \mathrm{~nm}$, and a shoulder at $c a .270 \mathrm{~nm}$. TD-DFT calculations for $\mathbf{A}_{2}$ were carried out using a range of functionals (CAM-B3LYP, PBE0 and M06-2X) and good agreement with experiment was found with CAM-B3LYP. These calculations suggest that the major peak in each spectrum corresponds to coincident aromatic $\pi \rightarrow \pi^{*}$ and $S_{0} \rightarrow S_{2}$ (see Fig. 5(b)) transitions and the shoulder peak corresponds to $S_{0} \rightarrow S_{1}$ (see Fig. 5(a)). The transition electron density plots (Fig. 5) indicate that both transitions result in a significant delocalisation of electron density from the $\mathrm{P}$ lone pairs. The first triplet state, accessible from

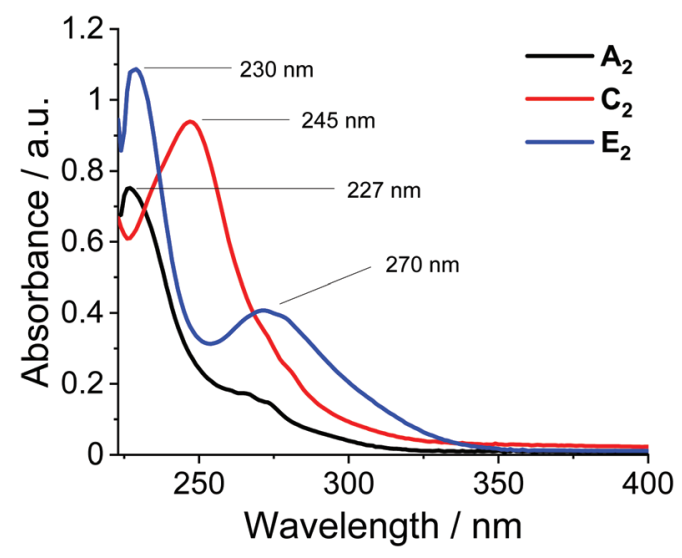

Fig. 4 UV-vis spectra of $A_{2}, C_{2}$ and $E_{2}$ in $\mathrm{CH}_{2} \mathrm{Cl}_{2}(20 \mu \mathrm{M})$. (a)

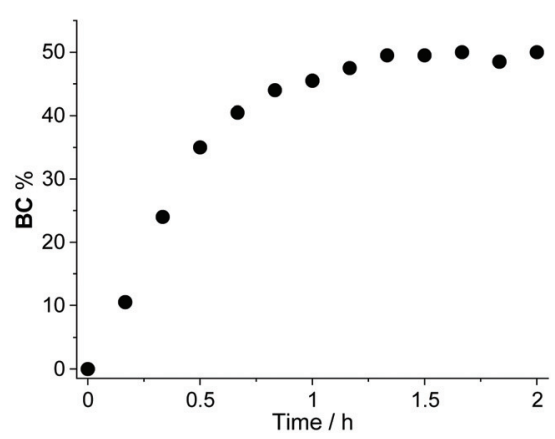

(b)

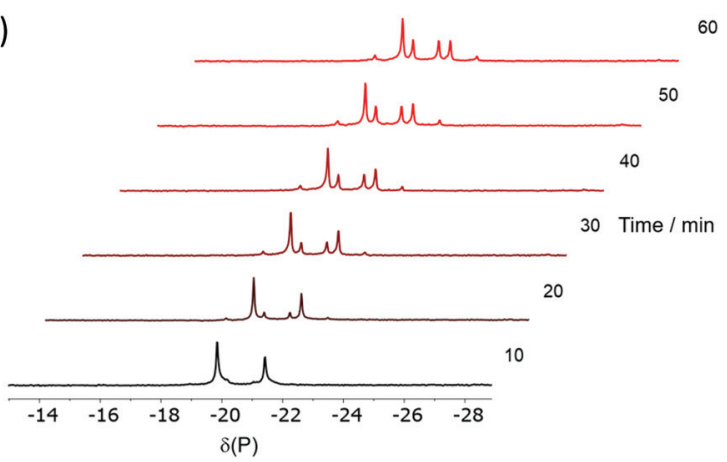

Fig. 3 (a) Plot of heterodiphosphane $B C$ formation as a function of time over $2 h$; (b) ${ }^{31} P\left\{{ }^{1} H\right\}$ NMR spectra of the reaction between $B_{2}$ and $C_{2}$ at $-20^{\circ} \mathrm{C}$ in THF, shown in $10 \mathrm{~min}$ increments over the course of $1 \mathrm{~h}$ (with inverse-gated decoupling). See Fig. 1 for the peak assignments. 
(a)

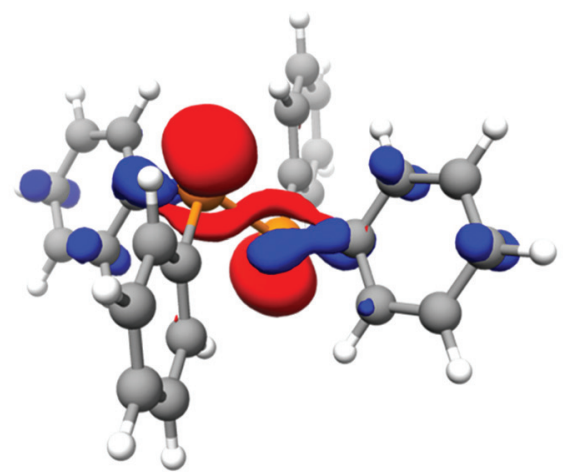

(b)

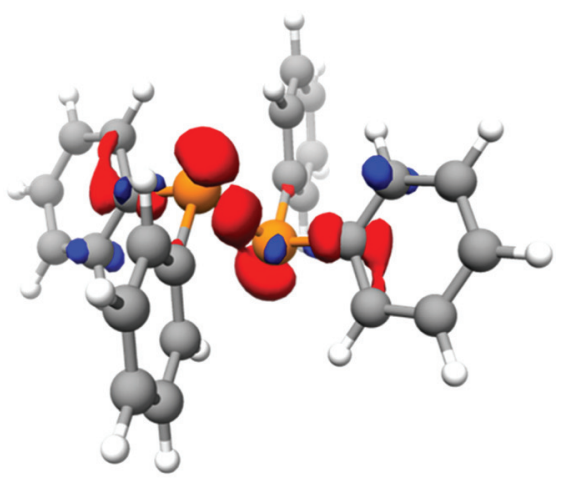

Fig. 5 Transition electron density difference plots with the CAM-B3LYP/def2-TZVPP//PBE0-D3BJ/def2-SVP level of theory. (a) $\mathrm{S}_{0} \rightarrow \mathrm{S}_{1}$ and (b) $\mathrm{S}_{0} \rightarrow \mathrm{S}_{2}$. Red and blue correspond to areas of depleted and excess electron density, respectively. Isosurface plotted at a contour of $0.003 \mathrm{au}$.

either $\mathrm{S}_{1}$ or $\mathrm{S}_{2}$ via intersystem crossing, is dissociative, leading to spontaneous formation of phosphinyl radicals. There are small differences in the three spectra shown in Fig. 4. As expected, the $p$-OMe groups in $\mathbf{C}_{2}$ produce a bathochromic shift in the $\pi \rightarrow \pi^{*}$ band and there is a long 'tail' that extends towards the visible region, which explains why $\mathbf{C}_{2}$ is pale yellow.

The evidence in support of radicals being present led to the radical chain mechanism proposal in Scheme 9 where homolysis of the $\mathrm{Ar}_{2} \mathrm{P}-\mathrm{PAr}_{2}$ is followed by attack of the $\mathrm{Ar}_{2} \mathrm{P}^{*}$ on the second diphosphane $\mathrm{Ar}_{2}{ }_{2} \mathrm{P}-\mathrm{PAr}_{2}{ }_{2}$. The termination steps are then the radical couplings with P-P bond formation.

The photodissociation requires UV radiation and it appears that there is sufficient background UVA-UVB radiation $(280-400 \mathrm{~nm})$ for the initiation step to proceed.

The two degenerate propagating steps, where $\mathrm{Ar}_{2} \mathrm{P}^{\bullet}$ and $\mathrm{Ar}_{2}{ }_{2} \mathrm{P}^{*}$ react with their respective dimers $\mathrm{Ar}_{2} \mathrm{P}-\mathrm{PAr}_{2}$ and $\mathrm{Ar}_{2}{ }_{2} \mathrm{P}-\mathrm{PAr}_{2}{ }_{2}$, are omitted from Scheme 9. The reverse P,P-metathesis process
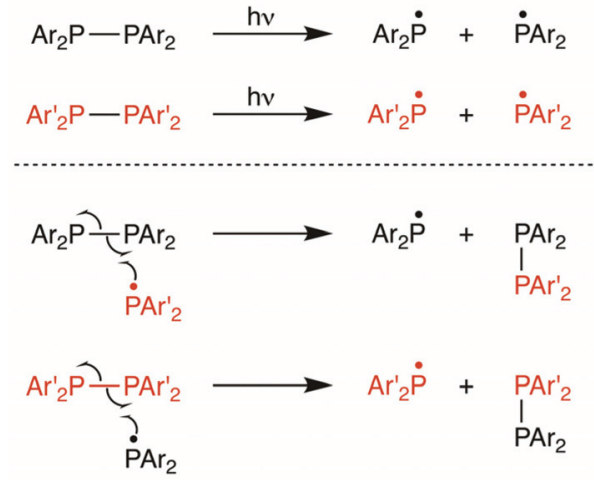

$$
\begin{aligned}
& \mathrm{Ar}_{2} \dot{\mathrm{P}}+\dot{\mathrm{PAr}}_{2} \longrightarrow \mathrm{Ar}_{2} \mathrm{P}-\mathrm{PAr}_{2} \\
& \mathrm{Ar}_{2} \dot{\mathrm{P}}+\dot{\mathrm{PAr}}_{2} \longrightarrow \mathrm{Ar}_{2} \mathrm{P}-\mathrm{PAr}_{2} \text { termination } \\
& \mathrm{Ar}_{2} \dot{\mathrm{P}}+\dot{\mathrm{PAr}}_{2} \longrightarrow \mathrm{Ar}_{2} \mathrm{P}-\mathrm{PAr}_{2}
\end{aligned}
$$

Scheme 9 would also be initiated by photodissociation of $\mathrm{Ar}_{2} \mathrm{P}-\mathrm{PAr}_{2}$. The P,P-metathesis reactions generally proceed with a high degree of chemoselectivity but traces of $\mathrm{Ar}_{2} \mathrm{PH}$ were often evident after several days of reaction which would arise from termination via abstraction of an $\mathrm{H}$ radical, presumably from the solvent.

The radical mechanism for diphosphane metathesis in Scheme 9 is reminiscent of the radical mechanism for disulfide metathesis (Scheme 10) arrived at from calculations by Ruipérez et $a l .{ }^{52}$ and from experimental observations by Asua et $a l^{53}$ DFT and MD calculations were applied to two mechanisms of diaryldisulfide metathesis: a [2+2] concerted metathesis and a $[2+1]$ radical chain reaction initiated by sulfanyl radicals (ArS $\left.{ }^{\circ}\right){ }^{47}$ The transition state in the concerted process was calculated to be too high in energy to be viable, whereas the radical process was viable provided the Ars" radicals could be accessed. This reasoning mirrors ours for the mechanisms proposed for diphosphane metatheses shown in Scheme 7.

It has been reported that the diaryldisulfide metathesis between diphenyldisulfide and di(4-aminophenyl)disulfide proceeds spontaneously to equilibrium in $c a .12 \mathrm{~h}$; this was accelerated by UV photolysis, and TEMPO completely inhibited the equilibration. ${ }^{53}$ These observations made on the disulfide metathesis reactions (and analogous diselenide studies) ${ }^{54}$ are very similar to our observations on the diphosphane metatheses.

\section{Anomalous kinetics with $(o-T o l){ }_{2} \mathrm{P}-\mathrm{P}(o-\mathrm{Tol})_{2}$}

The four P,P-metathesis reactions between tetra(o-tolyl)diphosphane $\left(\mathbf{E}_{2}\right)$ and $\mathbf{A}_{2}-\mathbf{D}_{2}$ did not appear to proceed at all in THF, $\mathrm{PhMe}, \mathrm{PhCl}, \mathrm{PhF}$ or $\mathrm{C}_{6} \mathrm{D}_{6}$ under ambient conditions after $72 \mathrm{~h}$ but do proceed in the chloroalkanes $\mathrm{CH}_{2} \mathrm{Cl}_{2}$ and $\mathrm{CHCl}_{3}$, albeit slowly (see Table 1, entries 7-10). To probe this anomalous behaviour further, we have investigated the $\mathbf{A}_{\mathbf{2}} / \mathbf{E}_{\mathbf{2}}$ system (Fig. 6) in more detail including approaching the equilibrium starting from an $\mathbf{A}_{2} / \mathbf{E}_{2}$ mixture and starting from isolated $\mathbf{A E}$.

$$
\mathrm{Ar}^{\prime} \mathrm{S}-\mathrm{SAr}^{\prime}+\mathrm{ArS}-\mathrm{SAr} \rightleftharpoons 2 \mathrm{Ar}^{\prime} \mathrm{S}-\mathrm{SAr}
$$




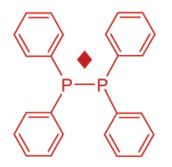

$\mathrm{A}_{2}$

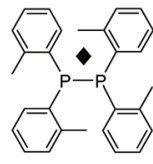

$E_{2}$

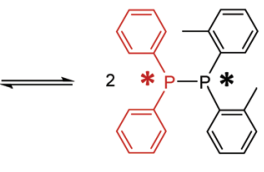

AE (a)

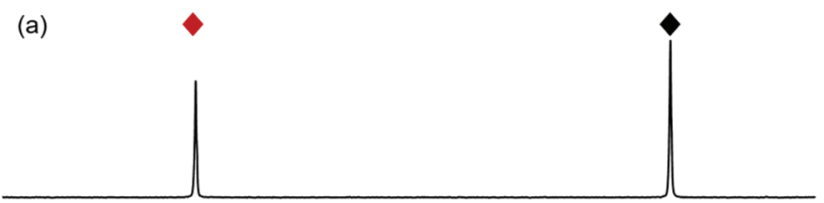

(b)

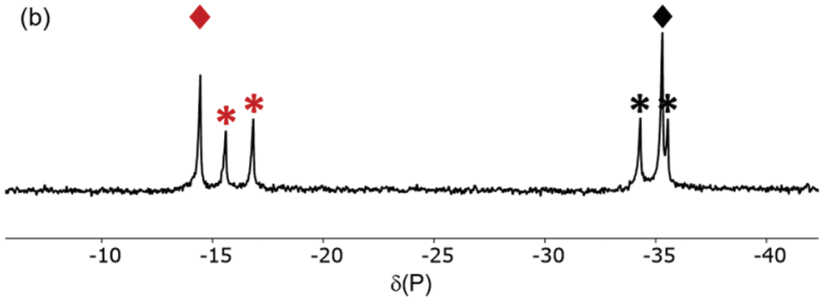

Fig. $6{ }^{31} P\left\{{ }^{1} H\right\} N M R$ spectra for the mixture of $A_{2}$ and $E_{2}$ : (a) in toluene after $48 \mathrm{~h}$, showing no detectable P,P-metathesis; (b) in $\mathrm{CDCl}_{3}$ after $6 \mathrm{~h}$, showing equilibrium with $\mathrm{AE}$ has been established.

The progress of the $\mathbf{A}_{\mathbf{2}} / \mathbf{E}_{\mathbf{2}}$ metathesis in $\mathrm{CDCl}_{3}$ was followed by ${ }^{31} \mathrm{P}$ NMR spectroscopy (see ESI $\dagger$ for details) with a spectrum recorded every $10 \mathrm{~min}$ for $12 \mathrm{~h}$ (see Fig. 7). The approach to equilibrium was measured from integration of the ${ }^{31} \mathrm{P}$ NMR signals to produce the plot shown in Fig. 7. Analysis of the curve revealed that it was not consistent with the integrated equations for an order of reaction of $0, \frac{1}{2}, 1$ or 2 ; this indicates that the kinetics are complex, which would be expected if more than one mechanistic pathway was operating (see below).

Evidence for radicals in the anomalous $(o-T o l)_{2} \mathrm{P}-\mathrm{P}(\boldsymbol{o}-\mathrm{Tol})_{2}$ metathesis reactions

There are several pieces of evidence supporting a role for radicals in the P,P-metathesis equilibrium shown in Fig. 6:
(1) The lack of any reaction between $\mathbf{A}_{2}$ and $\mathbf{E}_{2}$ in THF after $72 \mathrm{~h}$ was replaced by $30 \% \mathbf{A E}$ formation when the solution was irradiated with a UV lamp for $2 \mathrm{~h}$. Similarly, no equilibration was observed in a THF solution of pure $\mathbf{A E}$ over a period of $72 \mathrm{~h}$ but proceeded smoothly over $2 \mathrm{~h}$ upon irradiation of the same solution with a UV lamp. This suggests that the photodissociation mechanism shown in Scheme 6 for the general P,P-metathesis (Table 1, entries 1-6) is viable for the $\mathbf{A}_{\mathbf{2}} / \mathbf{E}_{\mathbf{2}}$ metathesis but requires a more intense source of UV radiation than background UV for the initiation step.

(2) The slow $\mathbf{A}_{2} / \mathbf{E}_{2}$ metathesis equilibration in $\mathrm{CDCl}_{3}$ which takes place over a period of $12 \mathrm{~h}$ was extinguished in the presence of 4 equiv. of the radical scavenger TEMPO, as no AE was detected after $16 \mathrm{~h}$.

(3) Pulse-sonication $(20 \mathrm{kHz})$ at $0{ }^{\circ} \mathrm{C}$ of a $\mathrm{CHCl}_{3}$ or $\mathrm{CH}_{2} \mathrm{Cl}_{2}$ solution of $\mathbf{A}_{2}$ and $\mathbf{E}_{2}$ reduced the time to establish equilibrium from $12 \mathrm{~h}$ to $<1 \mathrm{~h}$. However, sonolysis had no accelerating effects on the reaction of $\mathbf{A}_{2}$ with $\mathbf{E}_{2}$ in THF or toluene. Fritze and von Delius reported the metathesis of disulfides (Scheme 10) in chloroform was accelerated by sonolysis and suggested that this proceeded via $\mathrm{RS}^{\bullet}$ radicals formed from the reaction of disulfides with $\mathrm{Cl}^{*}$ generated by sonolytic chloroform degradation. ${ }^{16}$

(4) The onset of equilibration of solutions of $\mathbf{A E}$ in $\mathbf{C D C l}_{3}$ was preceded by an induction period of up to $6 \mathrm{~h}$; moreover, the time required to establish the P,P-metathesis equilibrium from mixtures of $\mathbf{A}_{\mathbf{2}} / \mathbf{E}_{\mathbf{2}}$ in $\mathrm{CDCl}_{3}$ varied from 6 to $12 \mathrm{~h}$. These observations of rate-inconsistency are typical of radical processes. $^{55}$

In addition to the evidence for a radical-promoted process, it is shown below that there is evidence of chlorophosphine involvement in the $\mathbf{A}_{2} / \mathbf{E}_{2}$ metathesis.

Evidence for chlorophosphine intermediacy in the anomalous $(o-T o l){ }_{2} \mathrm{P}-\mathrm{P}(\mathrm{o} \text {-Tol })_{2}$ metathesis reactions

Under the conditions where a mixture of $\mathbf{A}_{\mathbf{2}}$ and $\mathbf{E}_{\mathbf{2}}$ in $\mathrm{CDCl}_{3}$ would reach equilibrium with $\mathbf{A E}$ within $12 \mathrm{~h}$, the presence of $\mathrm{H}_{2} \mathrm{O}$ (100 equiv.) suppressed the reaction to the extent that no (a)

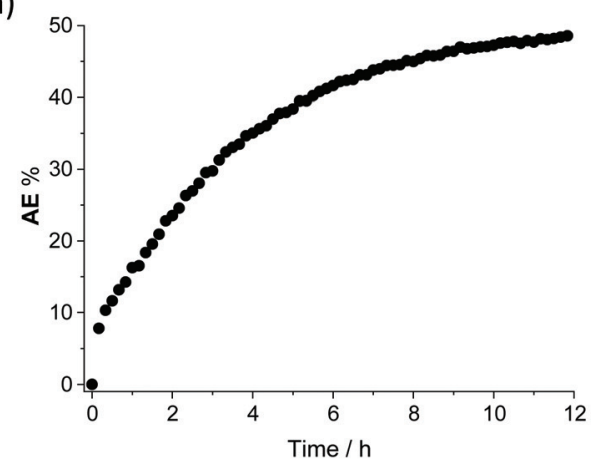

(b)

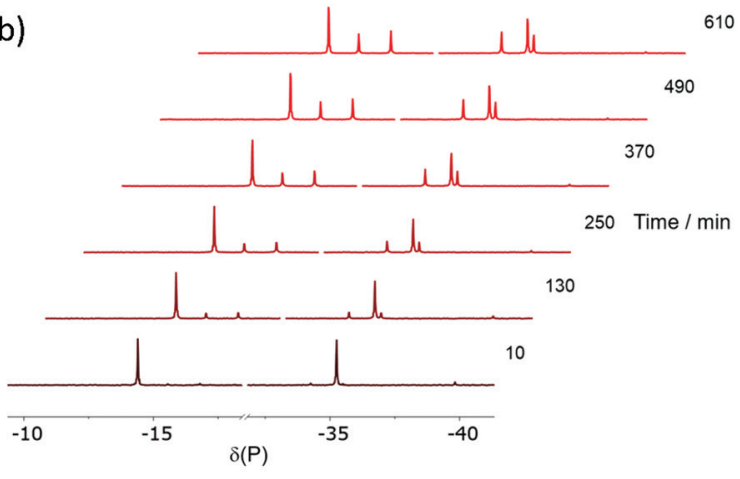

Fig. 7 (a) Plot of the data obtained from integration of the ${ }^{31} P\left\{{ }^{1} H\right\}$ NMR signals for the $A E$ formed in the reaction between diphosphanes $A_{2}$ and $E_{2}$; (b) ${ }^{31} \mathrm{P}\left\{{ }^{1} \mathrm{H}\right\}$ NMR spectra in $\mathrm{CDCl}_{3}$ obtained by sampling over $12 \mathrm{~h}$. See Fig. 6 for the peak assignments. 
AE was detected even after $20 \mathrm{~h}$ (indicating that $<1 \% \mathbf{A E}$ had been formed). Instead, several minor signals ( $c a .20 \%$ in total) were present and those at $\delta+23.5,+21.4$ were tentatively assigned to $\mathrm{Ar}_{2} \mathrm{P}(\mathrm{O}) \mathrm{H}(\mathrm{Ar}=\mathrm{Ph}$ or $o$-Tol). These observations are consistent with the water reacting rapidly with the $\mathrm{Ar}_{2} \mathrm{PCl}$ compounds that are formed. It is notable that the addition of water to the P,P-metathesis reaction mixture of $\mathbf{A}_{2}$ with $\mathbf{C}_{2}$ in $\mathrm{CDCl}_{3}$ had no discernible effect on the rapid formation of $\mathbf{A C}$ which indicates that $\mathrm{Ar}_{2} \mathrm{PCl}$ is not involved in the P,P-metathesis for this typical system.

When a solution of $\mathbf{A}_{2}$ alone in $\mathrm{CHCl}_{3}$ was irradiated with $\mathrm{UV}$, some conversion to $\mathrm{Ph}_{2} \mathrm{PCl}$ was observed directly. The stoichiometric reaction of $\mathbf{A}_{2}$ with $(o-\mathrm{Tol})_{2} \mathrm{PCl}$ in $\mathrm{CHCl}_{3}$ immediately produced a mixture of $\mathbf{A}_{2}, \mathbf{A E}$, and $\mathrm{Ar}_{2} \mathrm{PCl}(\mathrm{Ar}=\mathrm{Ph}, o$-Tol $)$ (Scheme 11) along with several unidentified P-containing species. After $4 \mathrm{~h}, \mathbf{E}_{2}$ was detected along with small amounts of secondary phosphines $\mathrm{Ar}_{2} \mathrm{PH}(\mathrm{Ar}=\mathrm{Ph}, \mathrm{o}$-Tol). These observations confirm that $\mathrm{Ar}_{2} \mathrm{PCl}$ compounds are plausible promoters of P,P-metathesis.

To explore whether $\mathrm{Ar}_{2} \mathrm{PCl}$ could catalyse $\mathrm{P}, \mathrm{P}-$ metathesis, a sub-stoichiometric amount (5 mol\%) of $\mathrm{Ph}_{2} \mathrm{PCl}$ was added to a chloroform solution of pure AE. The equilibration (Scheme 11) was then monitored by ${ }^{31} \mathrm{P}\left\{{ }^{1} \mathrm{H}\right\}$ spectroscopy and compared with the same process carried out in the absence of $\mathrm{Ph}_{2} \mathrm{PCl}$. In the absence of $\mathrm{Ph}_{2} \mathrm{PCl}$, equilibrium was established in $c a$. $70 \mathrm{~h}$, whereas in the presence of $5 \mathrm{~mol} \%$ of $\mathrm{Ph}_{2} \mathrm{PCl}$, equilibrium was established in $c a .7 \mathrm{~h}$ (see $\mathrm{ESI} \dagger$ ).

The key observations on the $\mathrm{P}, \mathrm{P}$-metathesis reaction between $\mathbf{E}_{2}$ and $\mathbf{A}_{2}$ are that: (1) the solvent $\left(\mathrm{CHCl}_{3}\right.$ or $\left.\mathrm{CH}_{2} \mathrm{Cl}_{2}\right)$ is critical for the reaction to proceed under ambient conditions; (2) the reaction has the characteristics of being radical-initiated; (c) $\mathrm{Ar}_{2} \mathrm{PCl}$ catalyses the $\mathrm{P}, \mathrm{P}$-metathesis.

It is known that $\mathrm{CHCl}_{3}$ is a source of $\mathrm{Cl}^{\circ}$ radicals (especially under photolysis ${ }^{56-60}$ or sonolysis ${ }^{61-64}$ ) and therefore the process shown in Scheme 12 is proposed in which the role of

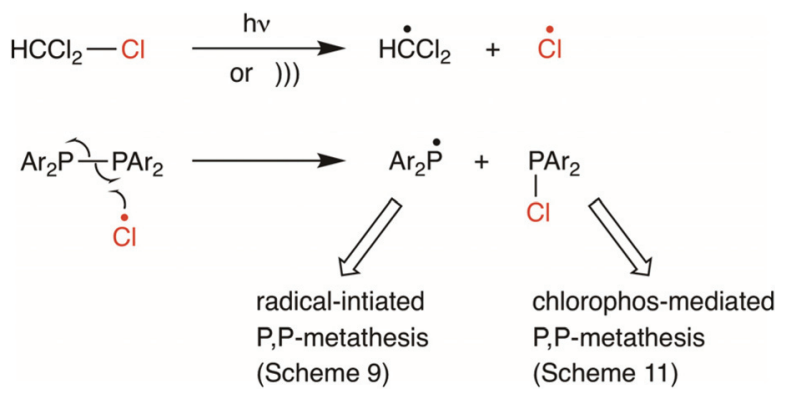

Scheme 12

$\mathrm{Cl}^{-}$is twofold: (a) to generate $\mathrm{Ar}_{2} \mathrm{PCl}$ which promotes the $\mathrm{P}, \mathrm{P}$ metathesis process (Scheme 11); (b) to form $\operatorname{Ar}_{2} \mathrm{P}^{\bullet}$ and initiate a radical chain $\mathrm{P}, \mathrm{P}-\mathrm{metathesis} \mathrm{process} \mathrm{similar} \mathrm{to} \mathrm{Scheme} 9$. DFT studies (see ESI $\dagger$ ) show that initiation by attack of $\mathrm{Cl}^{\bullet}$ on $\mathrm{Ar}_{2} \mathrm{P}-\mathrm{PAr}_{2}$ generating $\mathrm{Ar}_{2} \mathrm{P}^{*}$ (Scheme 12) is feasible: $\Delta G=$ $-35.3 \mathrm{kcal} \mathrm{mol}^{-1}$ and $\Delta G^{\ddagger}=3.4 \mathrm{kcal} \mathrm{mol}^{-1}$ (from the $\mathrm{Ph}_{2} \mathrm{P}-$ $\mathrm{PPh}_{2} \cdots \mathrm{Cl}^{\bullet}$ association complex).

The slow rate of the $\mathrm{P}, \mathrm{P}-\mathrm{m}$-tathesis reaction between the $o$-tolyl diphosphane $\mathbf{E}_{\mathbf{2}}$ and $\mathbf{A}_{\mathbf{2}}$ contrasts with the rapid rate of the $\mathrm{P}, \mathrm{P}$-metathesis reaction between the isomeric $p$-tolyl diphosphane $\mathbf{B}_{\mathbf{2}}$ and $\mathbf{A}_{\mathbf{2}}$. The explanation for the lower rates therefore lies in the proximity of the $o-\mathrm{CH}_{3}$ group to the $\mathrm{P}$-reaction centre. We have proposed that photolytic $\mathrm{Ph}_{2} \mathrm{P}^{\cdot}$ radical formation initiates the $\mathrm{P}, \mathrm{P}$-metathesis reactions of $\mathbf{A}_{\mathbf{2}}$ (see above) and, since the UV spectrum of $\mathbf{E}_{\mathbf{2}}$ resembles that of $\mathbf{A}_{2}$ (see Fig. 4), both $\mathrm{Ph}_{2} \mathrm{P}^{\bullet}$ and $(o-\mathrm{Tol})_{2} \mathrm{P}^{\bullet}$ radicals should be similarly accessible. We propose two tentative explanations for the role of the $o-\mathrm{CH}_{3}$ groups in $\mathbf{E}_{2}$. (1) The bulky $o$-tolyl substituents may be shielding $\mathbf{E}_{2}$ from radical attack by $\mathrm{Ph}_{2} \mathrm{P}^{\bullet}$ radicals or hindering radical attack by $(o-\mathrm{Tol})_{2} \mathrm{P}^{\cdot}$ on $\mathbf{A}_{2}$. Some support for a steric effect of an ortho-alkyl group on the rate of radical-initiated $\mathrm{P}, \mathrm{P}-\mathrm{metathesis}$ comes from calculations of

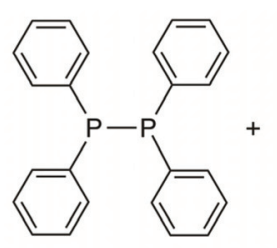

$\mathrm{A}_{2}$
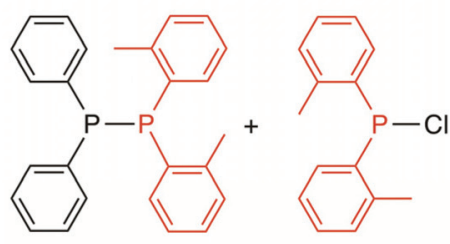

AE
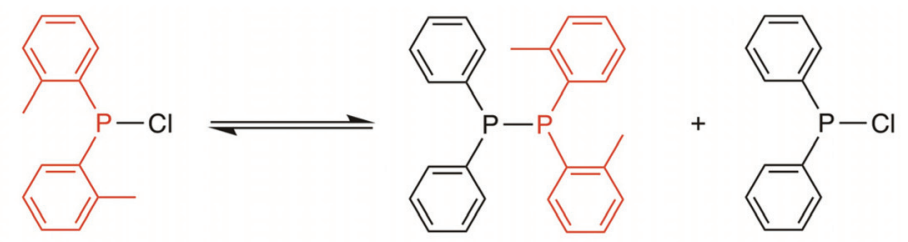

AE
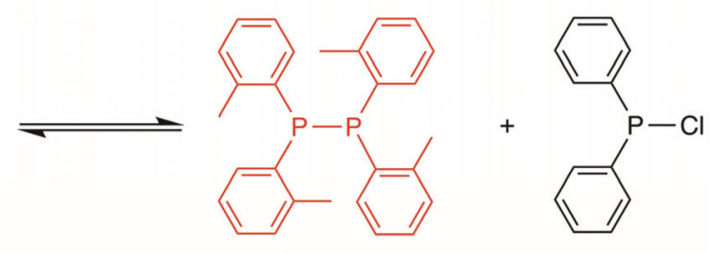

$E_{2}$

Scheme $11 \mathrm{P}, \mathrm{P}$-Metathesis promoted by $\mathrm{Ar}_{2} \mathrm{PCl}$. 


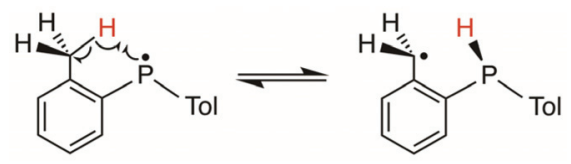

Scheme 13

$\Delta G^{*}$ for $\mathrm{Ar}_{2} \mathrm{P}^{\bullet}$ attack on $\mathrm{Ar}_{2} \mathrm{P}-\mathrm{PAr}_{2}$ where $\mathrm{Ar}=\mathrm{Ph}, o-\mathrm{C}_{6} \mathrm{H}_{4} \mathrm{Me}$ or $o-\mathrm{C}_{6} \mathrm{H}_{4}{ }^{t} \mathrm{Bu}$ which gave values of $5.5,6.7$ and $13.3 \mathrm{kcal} \mathrm{mol}^{-1}$ respectively (see ESI $\dagger$ for details). These show that, although the calculated $\Delta G^{\ddagger}$ values for $\mathrm{Ph}$ and $o-\mathrm{C}_{6} \mathrm{H}_{4} \mathrm{Me}$ are similar, for $o-\mathrm{C}_{6} \mathrm{H}_{4}{ }^{t} \mathrm{Bu}$, the calculated value is significantly greater. (2) Alternatively, the $o-\mathrm{CH}_{3}$ groups may provide a means of quenching the radical chain by $\mathrm{H}^{*}$ intramolecular abstraction from the proximal $\mathrm{CH}_{3}$ group to produce a benzylic radical by a process that is illustrated in Scheme 13. Calculations show that this would be highly unfavourable energetically (by $14.4 \mathrm{kcal} \mathrm{mol}^{-1}$ ) for the ground state $(o-\mathrm{Tol})_{2} \mathrm{P}^{\bullet}$ radical but the initially formed P-centred diphosphane radical would have sufficient energy for $\mathrm{H}$ transfer to take place (see ESI $\dagger$ for details). The energetic C-centred radical could then abstract $\mathrm{H}^{*}$ and the diphosphane reform thereby quenching the P,P-metathesis.

Both of these explanations are speculative and further work would be required to establish their veracity.

\section{Conclusions}

DFT calculations have shown that the thermodynamic stability of unsymmetrical diphosphanes $\left(\mathrm{Z}_{2} \mathrm{P}-\mathrm{PZ}_{2}{ }_{2}\right)$, with respect to their symmetrical analogues $\left(\mathrm{Z}_{2} \mathrm{P}-\mathrm{PZ}_{2}\right.$ and $\left.\mathrm{Z}_{2}^{\prime} \mathrm{P}-\mathrm{PZ}_{2}^{\prime}\right)$, should increase with increasing difference in the electronegativity and/or steric bulk of the $\mathrm{PZ}_{2}$ and $\mathrm{PZ}_{2}{ }_{2}$ constituents. In these terms, the observed stability of $\mathrm{Me}_{2} \mathrm{P}-\mathrm{P}\left(\mathrm{CF}_{3}\right)_{2}$ and ${ }^{t} \mathrm{Bu}_{2} \mathrm{P}-\mathrm{PPh}_{2}$ can be understood.

The unsymmetrical diphosphanes $\left(\mathrm{Ar}_{2} \mathrm{P}-\mathrm{PAr}_{2}^{\prime}\right)$ have been shown to be in finely balanced equilibria with their symmetrical analogues $\mathrm{Ar}_{2} \mathrm{P}-\mathrm{PAr}_{2}$ and $\mathrm{Ar}_{2}{ }_{2} \mathrm{P}-\mathrm{PAr}_{2}{ }_{2}$ which reflects their insensitivity to the aryl substituents employed ( $\mathrm{Me}, \mathrm{MeO}, \mathrm{CF}_{3}$ ). Significantly, the P,P-metathesis equilibria with the tetra-aryldiphosphanes were generally established rapidly $(<10 \mathrm{~min})$ at ambient temperatures, in a range of solvents, even in dilute solution; furthermore, the rate was increased by photolysis and inhibited by radical scavengers. The experimental and computational evidence points to the involvement of $\operatorname{Ar}_{2} \mathrm{P}^{\bullet}$ radicals generated photochemically.

Exceptional behaviour has been observed in the P,P-metathesis reactions involving $(o-\mathrm{Tol})_{2} \mathrm{P}-\mathrm{P}(o-\mathrm{Tol})_{2}$. These were only observed under UV-radiation or when the reactions were carried out in $\mathrm{CHCl}_{3}$ and $\mathrm{CH}_{2} \mathrm{Cl}_{2}$. The evidence supporting the involvement of $\mathrm{Ar}_{2} \mathrm{PCl}$ in the metatheses with $(o-\mathrm{Tol})_{2} \mathrm{P}-\mathrm{P}(o-\mathrm{Tol})_{2}$ in chlorinated solvents includes the effect of the presence of $\mathrm{H}_{2} \mathrm{O}$ : no P,P-metathesis is observed and the formation of hydrolysis products $\left.\mathrm{Ar}_{2} \mathrm{P}=\mathrm{O}\right) \mathrm{H}$ is detected. By contrast, the $\mathrm{P}, \mathrm{P}$-metatheses involving other $\mathrm{Ar}_{2} \mathrm{P}-\mathrm{PAr}_{2}$ proceed uninhibited by the presence of water and no $\operatorname{Ar}_{2} \mathrm{P}(=\mathrm{O}) \mathrm{H}$ species are detected.
The facility with which diphosphanes undergo P,P-metathesis is similar to the S,S-metathesis with disulfides and Se, Se-metathesis with diselenides. This augurs well for the application of diphosphanes in dynamic covalent chemistry.

\section{Conflicts of interest}

There are no conflicts to declare.

\section{Acknowledgements}

This research was funded by the Engineering and Physical Sciences Research Council through the EPSRC Centre for Doctoral Training in Advanced Composites for Innovation and Science (grant number EP/L0160208/1). We thank the Department of Chemistry at Oxford and the Centre for Computational Chemistry in Bristol for access to computing facilities.

\section{References}

1 S. Ulrich, Acc. Chem. Res., 2019, 52, 510-519.

2 X. Yan, F. Wang, B. Zheng and F. Huang, Chem. Soc. Rev., 2012, 41, 6042-6065.

3 S. Nevejans, N. Ballard, M. Fernández, B. Reck, S. J. García and J. M. Asua, Polymer, 2019, 179, 121670.

4 H. Geng, Y. Wang, Q. Yu, S. Gu, Y. Zhou, W. Xu, X. Zhang and D. Ye, ACS Sustainable Chem. Eng., 2018, 6, 15463-15470.

5 M. Chen, L. Zhou, Y. Wu, X. Zhao and Y. Zhang, ACS Macro Lett., 2019, 8, 255-260.

6 J. Xia, T. Li, C. Lu and H. Xu, Macromolecules, 2018, 51, $7435-7455$.

7 J. Liu, Y. Liu, Y. Wang, J. Zhu, J. Yu and Z. Hu, Mater. Today Commun., 2017, 13, 282-289.

8 C. Luo, X. Shi, Z. Lei, C. Zhu, W. Zhang and K. Yu, Polymer, 2018, 153, 43-51.

9 M. Irigoyen, A. Fernández, A. Ruiz, F. Ruipérez and J. M. Matxain, J. Org. Chem., 2019, 84, 4200-4210.

10 J.-C. Lai, L. Li, D.-P. Wang, M.-H. Zhang, S.-R. Mo, X. Wang, K.-Y. Zeng, C.-H. Li, Q. Jiang, X.-Z. You and J.-L. Zuo, Nat. Commun., 2018, 9, 2725.

11 I. Azcune and I. Odriozola, Eur. Polym. J., 2016, 84, 147-160.

12 S. P. Black, J. K. M. Sanders and A. R. Stefankiewicz, Chem. Soc. Rev., 2014, 43, 1861-1872.

13 P. Frei, R. Hevey and B. Ernst, Chem. - Eur. J., 2019, 25, 6073.

14 R. Martin, A. Rekondo, A. R. De Luzuriaga, P. Casuso, D. Dupin, G. Cabañero, H. J. Grande and I. Odriozola, Smart Mater. Struct., 2016, 25, 084017.

15 Y. Amamoto, H. Otsuka, A. Takahara and K. Matyjaszewski, Adv. Mater., 2012, 24, 3975-3980.

16 U. F. Fritze and M. von Delius, Chem. Commun., 2016, 52, 6363-6366.

17 Y. Chen and R. P. Sijbesma, Macromolecules, 2014, 47, 3797-3805. 
18 M. V. Encina, E. Lissi, M. Sarasúa, L. Gargallo and D. Radic, J. Polym. Sci., Polym. Lett. Ed., 1980, 18, 757-760.

19 K. L. Berkowski, S. L. Potisek, C. R. Hickenboth and J. S. Moore, Macromolecules, 2005, 38, 8975-8978.

20 H. Xu, W. Cao and X. Zhang, Acc. Chem. Res., 2013, 46, 1647-1658.

21 C. Liu, J. Xia, S. Ji, Z. Fan and H. Xu, Chem. Commun., 2019, 55, 2813-2816.

22 N. K. Kildahl, J. Chem. Educ., 1995, 72, 423-424.

23 I. V. Koval, Russ. Chem. Rev., 1994, 63, 735-750.

24 S. Burck, D. Gudat and M. Nieger, Angew. Chem., Int. Ed., 2004, 43, 4801-4804.

25 S. Burck, K. Götz, M. Kaupp, M. Nieger, J. Weber, J. S. auf der Günne and D. Gudat, J. Am. Chem. Soc., 2009, 131, 10763-10774.

26 N. Szynkiewicz, Ł. Ponikiewski and R. Grubba, Dalton Trans., 2018, 47, 16885-16894.

27 D. L. Dodds, M. F. Haddow, A. G. Orpen, P. G. Pringle and G. Woodward, Organometallics, 2006, 25, 5937-5945.

28 G. Bettermann, H. Buhl, R. Schmutzler, D. Schomburg and U. Wermuth, Phosphorus Sulfur, 1983, 18, 77-80.

29 N. A. Giffin, A. D. Hendsbee, T. L. Roemmele, M. D. Lumsden, C. C. Pye and J. D. Masuda, Inorg. Chem., 2012, 51, 11837-11850.

30 D. Gudat, Acc. Chem. Res., 2010, 43, 1307-1316.

31 M. Blum, O. Puntigam, S. Plebst, F. Ehret, J. Bender, M. Nieger and D. Gudat, Dalton Trans., 2016, 45, 19871997.

32 A. H. Cowley, Chem. Rev., 1965, 65, 617-634.

33 H. Nöth and H.-J. Vetter, Chem. Ber., 1963, 96, 1479-1484.

34 K. Issleib and W. Seidel, Chem. Ber., 1959, 92, 2681-2694.

35 A. K. King, A. Buchard, M. F. Mahon and R. L. Webster, Chem. - Eur. J., 2015, 21, 15960-15963.

36 S. Molitor, J. Becker and V. H. Gessner, J. Am. Chem. Soc., 2014, 136, 15517-15520.

37 M. C. Fermin and D. W. Stephan, J. Am. Chem. Soc., 1995, 117, 12645-12646.

38 V. P. W. Böhm and M. Brookhart, Angew. Chem., Int. Ed., 2001, 40, 4694-4696.

39 R. Waterman, Organometallics, 2007, 26, 2492-2494.

40 G. Fritz, in Advances in Inorganic Chemistry, ed. H. J. Emeleus and A. G. Sharpe, Academic Press, 1987, vol. 31, pp. 171-214.

41 K. O. Feldmann and J. J. Weigand, J. Am. Chem. Soc., 2012, 134, 15443-15456.

42 A. D. Gorman, J. A. Cross, R. A. Doyle, T. R. Leonard, P. G. Pringle and H. A. Sparkes, Eur. J. Inorg. Chem., 2019, 2019, 1633-1639.
43 N. A. Giffin, A. D. Hendsbee and J. D. Masuda, Dalton Trans., 2016, 45, 12636-12638.

44 N. Szynkiewicz, L. Ponikiewski and R. Grubba, Chem. Commun., 2019, 55, 2928-2931.

45 S. Kawaguchi and A. Ogawa, Asian J. Org. Chem., 2019, 8, 1164-1173.

46 R. K. Harris, E. M. Norval and M. Fild, Dalton Trans., 1979, 825-831.

47 A. A. M. Ali and R. K. Harris, Dalton Trans., 1988, 27752780.

48 A. Molloy, G. Sánchez-Sanz and D. Gilheany, Inorganics, 2016, 4, 36.

49 D. L. Dodds, J. Floure, M. Garland, M. F. Haddow, T. R. Leonard, C. L. McMullin, A. G. Orpen and P. G. Pringle, Dalton Trans., 2011, 40, 7137-7146.

50 L. R. Avens, L. V. Cribbs and J. L. Mills, Inorg. Chem., 1989, 28, 205-211.

51 T. Heurich, Z.-W. Qu, S. Nožinović, G. Schnakenburg, H. Matsuoka, S. Grimme, O. Schiemann and R. Streubel, Chem. - Eur. J., 2016, 22, 10102-10110.

52 J. M. Matxain, J. M. Asua and F. Ruipérez, Phys. Chem. Chem. Phys., 2016, 18, 1758-1770.

53 S. Nevejans, N. Ballard, J. I. Miranda, B. Reck and J. M. Asua, Phys. Chem. Chem. Phys., 2016, 18, 2757727583.

54 S. Ji, W. Cao, Y. Yu and H. Xu, Angew. Chem., Int. Ed., 2014, 53, 6781-6785.

55 X. Xu and P. D. Pacey, Phys. Chem. Chem. Phys., 2001, 3, 2836-2844.

56 B. M. Harvey and P. E. Hoggard, Photochem. Photobiol., 2014, 90, 1234-1242.

57 K. Tsujikawa, H. Segawa, K. Kuwayama, T. Yamamuro, T. Kanamori, Y. T. Iwata and T. Ohmori, Forensic Toxicol., 2020, 38, 475-480.

58 K. E. Maudens, S. M. R. Wille and W. E. Lambert, J. Chromatogr. B: Anal. Technol. Biomed. Life Sci., 2007, 848, 384-390.

59 C. Crabb and L. McDonald, US Pat, 3641169A, 1968.

60 S. Kawai, Yakugaku Zasshi, 1966, 86, 1125-1132.

61 H. M. Hung and M. R. Hoffmann, J. Phys. Chem. A, 1999, 103, 2734-2739.

62 V. Sáez, M. D. Esclapez, P. Bonete, D. J. Walton, A. Rehorek, O. Louisnard and J. González-García, Ultrason. Sonochem., 2011, 18, 104-113.

63 B. Park, E. Cho, H. Park and J. Khim, Jpn. J. Appl. Phys., 2011, 50, 07HE10.

64 M. Lim, Y. Son, J. Yang and J. Khim, Jpn. J. Appl. Phys., 2008, 47, 4123. 